\title{
The Effect of Longevity on Pensions in the Nigerian Pension Scheme
}

\author{
${ }^{1}$ Dr. Martin Osawaru Omorodion, ${ }^{2}$ Rapheal Onyechefule Akalonu \\ ${ }^{1}$ Joseph Ayo Babalola University, Ikeji - Arakeji, Osun State \\ ${ }^{2}$ Redeemer UniversityMowe, Ogun State.
}

\begin{abstract}
The old pension scheme pension were based on length of service and on a percentage of final salaries. In the new pension scheme contributions are invested till retirement. Accumulated contributions are used to purchase pension at retirement. The paper looks at the effect of longevity on the annuity values at retirement and the consequent pensions. Three lives age 25, 35 and 45 with 35, 25 and 15 years to retirement are considered.

Five Life Tables with life expectancies of 13.48, 14.43, 15.61, 17.98 and 19.51 years at age 60 each were considered. We find that the new pension rate is considerably less than the old rate for each Life Table and longevity increases annuity value, thereby reducing pensions.

The percentage goes from 100\% to $82.8 \%$ taking the Life .Table with the least life expectancy as a base and for a life aged 25.The same result follows for each life considered,
\end{abstract}

Key words: Life Table, Longevity, annuities, asset accumulation, and pensions.

\section{Introduction}

In 2004, a new Pension Act replaced the old Pension Act. of 1979. The new pension scheme is a defined contribution scheme unlike the old pension scheme which was a defined benefit scheme. In the new scheme retirement benefit are based on the accumulated funds from investments over the employee length of service and the quantum of pension that can be purchased at retirement taking into consideration all the dependent actuarial functions. The annuity value or cost depends on these actuarial functions of which the Life Table is one of such.

This paper examines the effect of longevity on annuity cots which determines the quantum of pension for various life expectancies.

In the old scheme survival functions were not taking into consideration since pensions was a percentage of final emolument at retirement and did not depend on annuity value or cost.

\section{Literature Review}

Minton and Miller in their paper Pension Plans still at Risk from Global Economic Downturn considered embedding pension risk in an overall risk framework, measuring risk against clear and consistence metrics and the balance short- term volatility with long -term goals.

They emphasized the need to implement clearly defined, consistent metrics that evaluate the interaction of pension assets and liabilities.

Also in their paper, they indicated that from a survey conducted covering nearly 42 million plan participant, the findings reveal that "the risks that receive the most attention are typically asset - centric and easiest to model measure.

(i.e asset allocation, meeting return goals, asset - liability mismatch).

Lowery in his paper 'the future of Retirement and Employee benefit' stressed on the challenges faced by employers and pension provides "the volatility in the financial markets and increasing longevity impact defined benefit plan finding as well as defined contribution plan out comes".

\section{Assumption}

1. We assume that contribution come in every month and they are regular,

2. Employees are entitled to salary increments over years the and by a fixed percentage e.g $6 \%$ per annum.

3. Investments are in equities and fixed interest securities only.

4. Assets and liabilities are well matched.

5. The assumed rate of investment return is $10 \%$ for the combined returns on equities and fixed interest securities.

6. Annuity costs at retirement are actuarially fixed.

7. Annuities exist for the rest of life and not for 18 years only as it can be in the new pension scheme. 
8. $15 \%$ of emoluments remain the total contributions to the scheme throughout the working period of the employees.

9. Five Life Tables with life expectancies of 13.48, 14.43 and 15.61717 .98 and 19.51 at age 60 were assumed and designated them as L1, L2, L3, L4 and L5 Tables respectively.

10. We considered 3 lives aged 25, 35 and 45 years, having 35, 25 and 15 years to retirement at age 60. The rate of discounting is assumed to be $10 \%$ per annum.

\section{Methodology}

If $s$ is the annual salary increment and $i$ is the rate of assets return per annum, then a yearly investment of 1 for in years will amount to $S_{n}^{i}$ after n years where

$S_{n_{-}}^{i}=1+(1+\mathrm{i})+(1+\mathrm{i})^{i}+$ $(1+i)^{n-1}$

And with a yearly salary increment of $s \%$ (percent), asset accumulation will amount to

$(1+i)^{n}+(1+l)^{n-1}(1+s)+------+(1+i)(1+s)^{n-i}+(1+s)^{n}$

If $\mathrm{S}>i$

$(1+i)^{n}\left[1+\left(\frac{1+s}{1+i}\right)+-----+\left(\frac{(1+s)}{(1+2)}\right)^{n-i}+\left(\frac{1+s}{1+2}\right)^{n}\right]$

Let $1+i^{\prime \prime}=\frac{1+s}{1+i}$

Hence $\quad\left(1+i^{\prime \prime}\right)(1+i)=1+s$

$\mathrm{i}^{\prime \prime}\left(1+i^{\prime \prime}\right)=s-i$

$\mathrm{i}^{\prime \prime}=\frac{(s-i)}{(1+i)}$

If $\mathrm{i}>\mathrm{s}$,

$$
i^{\prime \prime}=\left(\frac{i-s}{1+s}\right)
$$

Hence with salary increment yearly asset accumulation will amount to

$S n 7^{i i}(1+i)^{n}, S>i$ or $S n 7^{i i}(1+s)^{n}$ if $i>s$.

Also let $l_{\mathrm{x}}$ be the number of lives serving at age $\mathrm{x}$ form $l_{0}$, the number of lives at birth.

Let $\mathrm{v}$ be the rate of discount.

Annuity $\mathrm{a}_{\mathrm{x}}$ payable at age $\mathrm{n}$

$\sum_{t=0} \frac{L_{x}+t V^{t}}{L_{x}}$

$\sum_{t=0} \frac{L x+t}{L x}-\frac{V^{x+t}}{v^{x}}=\sum_{t=0}^{\infty} \frac{D_{x+t}}{D_{x}}$

where $\mathrm{v}=(1+i)^{-1}$ and $\mathrm{D}_{x}=\mathrm{L}_{\mathrm{x}} \mathrm{v}^{\mathrm{x}}$

Hence an employee on a salary of A per annum with a salary increment who has $\mathrm{n}$ more years before retirement will have accumulated assets at retirement $=0.15 \mathrm{~A} s{ }_{n}^{i i}$

the value of annuity at age 60 is $\mathrm{a}_{60}$ then the pension payment. yearly will be

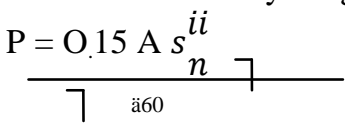

Probability that a life aged $\mathrm{x}$ survives to age $x+\mathrm{t}$ is $\underline{\mathrm{L} x+\mathrm{t}}$

Findings

$\mathrm{L}_{x}$

Table 1: Annuity value for each life Table

\begin{tabular}{|l|l|}
\hline Life Expectancy At 60 & Annuity Value at 60 \\
$\mathrm{~L}_{1}$ & 6.527 \\
$\mathrm{~L}_{2}$ & 6.873 \\
$\mathrm{~L}_{3}$ & 7.014 \\
$\mathrm{~L}_{4}$ & 7.320 \\
$\mathrm{~L}_{5}$ & 7.883 \\
\hline
\end{tabular}

Table 2Accumulated value of investments to 60 age for 3 lives aged 25,35 , and 45 years

\begin{tabular}{|l|l|}
\hline Age (Years) & Investment Accumulation \\
\hline 25 & 32.400 \\
35 & 6.975 \\
45 & 1.502 \\
\hline
\end{tabular}


TABLE 3: Annual Pensions for each Life Table

\begin{tabular}{|l|l|l|l|l|l|}
\hline Age & $\mathrm{L}_{1}$ & $\mathrm{~L}_{2}$ & $\mathrm{~L}_{3}$ & $\mathrm{~L}_{4}$ & $\mathrm{~L}_{5}$ \\
\hline 25 & 4.964 & 4.714 & 4.619 & 4.626 & 4.110 \\
\hline 35 & 1.069 & 1.015 & 0.994 & 0.953 & 0.885 \\
\hline 45 & 0.219 & 0.219 & 0.214 & 0.205 & 0.191 \\
\hline
\end{tabular}

Table 4: Annual Pensions of the Old Scheme

\begin{tabular}{|l|l|l|l|}
\hline Age of Life & Final Salary at Age 60 & Pension Rate as \% of Final Salary & Pension \\
\hline 25 & 7.686 & $80 \%$ & 6.149 \\
\hline 35 & 4.292 & $60 \%$ & 2.575 \\
\hline 45 & 2.397 & $40 \%$ & 0.959 \\
\hline
\end{tabular}

The above Pension is ignoring the fact that gratuity is in addition to the pension in the old scheme. If gratuities were to be take from the accumulate assets at age 60 in the new pension scheme the amount of accumulated for pensions purchase will be further reduced, we ignore this fact.

Table 5: Pension Relationship Of Longevity With Least Life Expectancy As A Base

\begin{tabular}{|c|c|c|c|c|c|}
\hline Age & $\mathrm{L}_{1}$ & $\mathrm{~L}_{2}$ & $\mathrm{~L}_{3}$ & $\mathrm{~L}_{4}$ & $\mathrm{~L}_{5}$ \\
\hline 25 & $100 \%$ & 95.000 & 93.0 & 89.2 & 82.8 \\
\hline 35 & $100 \%$ & 95.00 & 94.4 & 90.5 & 84.1 \\
\hline 45 & $100 \%$ & 100.00 & 97.7 & 93.6 & 87.2 \\
\hline $\begin{array}{l}\text { Ratio of } \\
\text { Expectancies Las } \\
\text { base }\end{array}$ & 1.0 & 1.070 & 1.158 & 1.334 & 1.447 \\
\hline
\end{tabular}

When we compare tables 3 and 4 we find that the new pension rate with the old pension scheme rate which is the relationship between defined benefit and defined contribution.

Table 6: Current Pension as a Percentage of Old Pension Scheme Life Table

\begin{tabular}{|l|l|l|l|l|l|}
\hline Age & $\mathrm{L}_{1}$ & $\mathrm{~L}_{2}$ & $\mathrm{~L}_{3}$ & $\mathrm{~L}_{4}$ & $\mathrm{~L}_{5}$ \\
\hline 25 & 80.7 & 76.7 & 75.1 & 72.0 & 6 \\
\hline 35 & 41.5 & 39.4 & 38.6 & 37.0 & 34.4 \\
\hline 45 & 22.8 & 22.8 & 22.3 & 21.4 & 21.4 \\
\hline
\end{tabular}

Looking at table 6 we find that the new pension rate at age 25 declines from $80.7 \%$ to 66.8 of the old pension rate as the life expectancy increases.

The new pensions declines from $41.5 \%$ to $34.4 \%$ of the old pension for a life age 35 . For a life aged 45years the new pensions decline from $22.8 \%$ to $21.4 \%$ of the old pension.

The drop in pensions for the new pensions as age increases for all the life expectancies is drastic.

From Tables 5, the new pension declines from $100 \%$, taking the lowest life expectancy as base to 82.8 for age 25 , to $84.1 \%$ for age 35 and and $87.2 \%$ for age 45 .

Longevity reduces the pensions and is more market as age increases.

\section{Conclusion}

The risk of reduction of pensions with the new pension scheme is considerable especially as the age of employee at commencement increases and years to retirement reduces. Longevity reduces the pensions at retirement considerable. longevity.

Employees should embark on a self additional pension plan to augment the short fall in pensions due to

\section{References}

[1]. CFO Research Service, creating benefits that work for employers and employees. 12 May 2012 CFO Publishing LLC

[2]. CFO Research Services, Greater employee Choice in the face of rising benefits, 4 May, 2012 Publishing LLC

[3]. Theresa Minton - Eversole and Stephen Miler. Pension plans still at risk from Global Economic Downturn. On line Editors forms SHRM, 2012 